\title{
Colaboração em ambientes de comunicação assíncrona: uma estratégia para o desenvolvimento profissional de professores de História
}

\author{
Andréia Assis Ferreira*
}

\begin{abstract}
Resumo
Neste artigo, exploramos o construto colaboração diferenciando-o de cooperação. Destacamos como a colaboração online em ambientes de comunicação assíncrona pode ser potencializadora do desenvolvimento profissional de professores de História. Apresentamos exemplos desta interação mediados pela ferramenta E-group, a partir dos resultados da investigação apresentados na tese de doutorado orientada pela Profa. Dra. Lana Mara de Castro Siman, financiada pelo CNPq, "Desenvolvimento profissional de professores de História: estudo de caso de um grupo colaborativos mediado pelas tecnologias aplicadas à educação," acerca do desenvolvimento profissional de professores de História da RME/BH, que vivenciaram um processo de formação e consolidação de um grupo colaborativo mediado pelas TICE (Tecnologias de informação e comunicação aplicadas à educação). Baseados no conceito de desenvolvimento profissional adotado por Garcia (1999) - como o conjunto de processos e estratégias que facilitam a reflexão dos professores sobre a sua prática, que contribui para que os professores gerem conhecimento prático, estratégico e sejam capazes de aprender com sua experiência - acreditamos que o grupo colaborativo pode ser um espaço desencadeador e propício para que essas reflexões ocorram.
\end{abstract}

Palavras-chave: Comunicação assíncrona; Colaboração; Lista de discussão; Desenvolvimento profissional de professores; TICE.

A sociedade contemporânea tem como uma de suas características marcantes a velocidade com que as informações, por meio das tecnologias digitais, podem ser transmitidas em tempo real para todas as partes do mundo, atingindo um amplo contingente de pessoas e tornando possível o rompimento das fronteiras tempo e espaço.

A constante disponibilização de diversas tecnologias de informação e comunicação facilitou o encontro, a organização, o intercâmbio, o debate e a visibilidade de comunidades virtuais, promovendo uma reorganização social.

\footnotetext{
* Doutora em Educação pela Universidade Federal de Minas Gerais (UFMG).
} 
No contexto educacional as tecnologias de informação e comunicação aplicadas à educação $(\mathrm{TICE})^{1}$ instituem novos sistemas de relações organizacionais, sociais e escolares. Para Silva, B. (2001) as TICE não são apenas meros instrumentos que possibilitam a emissão/recepção deste ou daquele conteúdo de conhecimento, mas também contribuem fortemente para condicionar e estruturar a ecologia comunicacional das sociedades. Cada época histórica e cada tipo de sociedade possui uma determinada configuração que lhe é devida e proporcionada pelo estado das suas tecnologias, reordenando de um modo particular as relações espaço temporais, nas suas diversas escalas (local, regional, nacional, global) que o homem manteve e mantém com o mundo, e estimulando e provocando transformações noutros níveis do sistema sociocultural (educativo, econômico, político, social, religioso, cultural etc.).

As TICE modificam os tempos, os ambientes e as formas habituais de nos relacionarmos com o processo de ensino e de aprendizagem. Criam novas formas de interagirmos uns com os outros, novas formas de acesso ao saber e de construção do conhecimento.

Consideramos que a inserção das TICE no trabalho docente pode potencializar o processo de desenvolvimento profissional dos professores e a abertura de caminhos para a construção e reformulação de uma nova prática. Como Costa (2004), também compreendemos que essas alterações, decorrentes da incorporação das TICE pelo coletivo de professores, podem trazer um novo contorno ao desenvolvimento profissional. Entretanto, para que isso aconteça, não é suficiente pensarmos apenas em artefatos tecnológicos, o aspecto fundamental da inserção das TICE na escola está na formação de professores, que devem receber uma preparação adequada à utilização consciente e crítica da tecnologia em sua prática pedagógica.

A inserção das TICE, bem como as reflexões acerca de suas possibilidades nas escolas, é essencial e necessária para contribuir na formação de um sujeito historicamente situado. Além disso, o professor não pode ficar alheio ao movimento imprimido pelas relações estabelecidas entre as tecnologias de informação e comunicação e a sociedade contemporânea. Acreditamos que as TICE podem propiciar participação do educando na construção do conhecimento, tornando o professor um

\footnotetext{
${ }^{1}$ Neste texto usaremos o termo Tecnologias da Informação e da Comunicação aplicadas à Educação, ao nos referirmos a toda forma de adquirir, gerar, armazenar, transmitir, processar e reproduzir informação, todos os meios de diversas linguagens e suportes (áudio, escrito, visual), contemplando as multimídias e a Internet, sendo que todas as variáveis e os aspectos envolvidos nesse processo deverão ser de natureza essencialmente pedagógica.
} 
mediador do processo de ensino-aprendizagem, possibilitando uma nova relação professor-aluno-conhecimento.

Um exemplo claro é a relação internet-professor-aluno. As possibilidades de uso da internet como ferramenta educacional estão crescendo e os limites dessa expansão são desconhecidos. A cada dia, surgem novas maneiras de usar a internet como recurso para enriquecer e favorecer os processos de ensino-aprendizagem. Da mesma forma, ela não deve ser simplesmente uma versão ampliada dos atuais métodos de busca de informação, mas sim uma ferramenta de complementação que possa enriquecer e contribuir para uma melhoria na sua qualidade, valorizando o papel do professor como mediador e orientador do processo de busca, seleção e utilização da informação relevante.

A literatura e a nossa própria experiência mostram que a inserção do computador em ambientes educacionais apresenta grandes desafios, uma vez que implica entender o computador como mediador do processo de ensino e aprendizagem, provocando um redimensionamento dos conceitos já conhecidos e cristalizados, ao mesmo tempo em que impulsiona à compreensão de novas ideias e valores. Requer, ainda, a análise cuidadosa do que significa ensinar e aprender, bem como demanda rever o papel do professor nesse contexto.

\section{Fundamentação da problemática em estudo}

\section{Cooperação e colaboração}

Há algum tempo, os conceitos cooperação e colaboração começam a ser aplicados de forma mais significativa no contexto da pesquisa educacional.

Apesar de semelhantes, cooperação e colaboração são formas de relacionamento distintas na essência de sua organização. Na cooperação, as pessoas trabalham juntas por uma meta que não necessariamente é de todos. A colaboração envolve maior reciprocidade e equidade através do projeto, ao passo que a cooperação admite responsabilidades e papéis mais variados. A colaboração requer a tomada de decisão conjunta; já a cooperação é frequentemente iniciada por uma parte, cabendo às demais proporcionar a ajuda e os serviços necessários.

Para Dillembourg (1999), a diferença entre a cooperação e a colaboração pode ser traduzida pelo modo como é organizada a tarefa pelo grupo. Para eles, na colaboração, todos trabalham em conjunto, sem distinções hierárquicas, em um esforço 
coordenado, a fim de alcançarem o objetivo ao qual se propuseram. Já na cooperação, a estrutura hierárquica prevalece e cada um dos membros da equipe é responsável por uma parte da tarefa.

Torres, Alcântara e Irala (2004), ao analisarem as distintas características dos construtos cooperação e colaboração, sintetizam que esses diversos conceitos designam atividades de grupo que pretendem um objetivo em comum. Apesar de suas diferenciações teóricas e práticas, ambos os conceitos derivam de dois postulados principais: de um lado, da rejeição ao autoritarismo à condução pedagógica com motivação hierárquica, unilateral, de outro, trata-se de concretizar uma socialização não só pela aprendizagem, mas principalmente na aprendizagem. Desta forma, esses dois propósitos se organizariam mediante um instrumento que equaciona a comunicação com tais características: trata-se de uma comunicação direta, contínua, construtiva.

Entendemos como Dillenbourg (1999) que, na cooperação, os membros do grupo dividem o trabalho, resolvem individualmente e então agrupam os resultados parciais na produção final. Na colaboração, os membros fazem o trabalho junto. Porém, alguma divisão espontânea pode acontecer até mesmo quando duas pessoas realmente trabalham juntas. Outro modo para definir colaboração é analisando como os membros interagem dentro de um trabalho colaborativo.

Para Day (1999), a colaboração representa uma forma particular de cooperação que envolve trabalho conjuntamente realizado de modo que os atores envolvidos aprofundem mutuamente o seu conhecimento. Por outro lado, esse autor usa a noção de cooperação para designar toda a investigação educacional realizada nas escolas, mesmo aquela em que os investigadores se limitam apenas a usar professores e alunos como fontes de dados. Indo ao mesmo sentido, Day refere que enquanto na cooperação as relações de poder e os papéis dos participantes no trabalho cooperativo não são questionados, a colaboração envolve negociação cuidadosa, tomada conjunta de decisões, comunicação efetiva e aprendizagem mútua num empreendimento que se foca na promoção do diálogo profissional.

Em síntese, caracterizamos o trabalho colaborativo, como aquele em que:

- a participação é voluntária e todos os envolvidos desejam crescer profissionalmente;

- a confiança e o respeito mútuo fundamentam todo o trabalho;

- os participantes trabalham juntos (co)-laboram por um objetivo comum 
construindo e compartilhando significados acerca do que estão fazendo e do que isso significa para suas vidas e para sua prática;

- os participantes se sentem à vontade para se expressar livremente e estão dispostos a ouvir críticas e a mudar;

- não existe uma verdade ou orientação única para as atividades. Cada participante pode ter diferentes interesses e pontos de vista, aportando distintas contribuições, ou seja, existirão diferentes níveis de participação (FERREIRA, 2010).

A colaboração envolve mudanças nas formas estabelecidas de convívio e hierarquia, uma vez que não pode ser imposta, mas precisa ser construída. Ao contrário das formas típicas de autoridade atribuídas aos papéis e relacionamentos institucionais, esse tipo de relacionamento propõe a incorporação de múltiplas perspectivas e o envolvimento dos indivíduos em um clima tal que sintam vontade de compartilhar suas diferenças e semelhanças.

No presente artigo utilizaremos o termo colaboração para designar o tipo de relacionamento no qual cada indivíduo participa da maioria das decisões: escolher a meta, definir as estratégias, definir as tarefas e avaliar o resultado. Isso o faz consciente de que é algo realmente importante para ele, algo que tanto beneficia o grupo como um todo, quanto a ele diretamente.

Focaremos a colaboração online mediada pela ferramenta E-group do servidor Yahoo. ${ }^{2}$ Essa ferramenta possibilita a troca de mensagens instantâneas, arquivamento de material (artigos, conclusões de fóruns, planos de aula, fotos, enquetes, fórum, entre outros).

Nesse sentido, a colaboração online pode proporcionar aos professores envolvidos oportunidades de refletir, articular e discutir seu conhecimento profissional, além de possibilitar que eles próprios experimentem novas formas de pensar o ensino.

\section{Desenvolvimento Profissional de Professores}

A variedade de significados atribuídos aos termos formação e desenvolvimento profissional, na literatura, deve-se ao fato de alguns autores atribuírem o mesmo sentido a esses termos e outros tentarem conceituá-los sob diferentes perspectivas ou paradigmas. Embora haja muitos pontos em comum entre os construtos formação de

\footnotetext{
${ }^{2}$ Disponível em: <http://br.groups.yahoo.com/group/grupoeleonorapierucetti>
} 
professores e desenvolvimento profissional, a utilização dos mesmos em investigações deve ser feita com cautela, haja vista que existem significativas diferenças entre eles.

A formação, por exemplo, tem subjacente uma lógica "escolar", enquanto o desenvolvimento profissional processa-se através de múltiplas formas e processos. A formação é construída tendo como pressuposto a carência do professor numa certa área do saber; no desenvolvimento profissional, parte-se do professor, das suas experiências, dos seus saberes, para desenvolvê-los (PONTE, 1998).

Segundo Costa (2004), a importância de encarar a formação na perspectiva do desenvolvimento profissional deriva da constatação de que uma sociedade em constante transformação impõe à escola responsabilidades cada vez maiores.

É exigida ao professor uma atitude de constante aprendizagem relacionada aos problemas que emergem da prática pedagógica, englobando os processos que melhoram o seu conhecimento profissional, seu grau de autonomia, suas relações com seus pares e as possibilidades de refletir sobre seu trabalho e condições em que esse se realiza.

Não podemos deixar de problematizar, no entanto, que nem sempre essas potencialidades são valorizadas, apoiadas e estimuladas. Na maioria das escolas não há organização de tempos para a troca de experiência e saberes, travando, muitas vezes, a implementação de projeto de inovação. É necessário que haja, portanto, um contexto favorável ao desenvolvimento profissional, um espaço rico em oportunidades, aberto às demandas do professor, atento aos saberes e experiências, e organizado de forma que possibilite o tempo e o espaço necessários para que a aprendizagem ocorra. Um espaço propício para práticas colaborativas de reflexão e investigação entre os professores.

Uma vez estabelecidos os contornos políticos que envolvem a formação dos professores, na perspectiva do desenvolvimento profissional, podemos dizer que o conceito de desenvolvimento profissional pressupõe, portanto, que o professor possa evoluir continuamente, incorporando/aprendendo os fundamentos de uma cultura profissional, que significa saber por que se faz, o que se faz e quando e por que será necessário fazê-lo de um modo distinto (IMBERNÓN, 2004). Desse modo, fatores relacionados com o contexto profissional e com as oportunidades de formação podem contribuir significativamente.

Nesse sentido, adotamos neste texto o construto desenvolvimento profissional e não formação inicial e continuada, para nos referirmos a um processo maior e mais complexo, que envolve tanto a formação inicial quanto à continuada, as experiências como aluno e professor. Esse processo pode ocorrer não apenas a partir de cursos, 
seminários e oficinas, mas também no dia a dia, na interação com colegas, pais e alunos, nas leituras e reflexões pessoais. Dessa forma, é um processo que envolve a aprendizagem de novos conhecimentos e habilidades que, gradativamente, passam a se refletir no discurso, nos saberes e na prática do professor.

\section{Lista de discussão - E-group}

As listas de discussão surgiram nos Estados Unidos na década de 70 como um sistema de comunicação assíncrona (os participantes não precisam estar simultaneamente conectados para que a comunicação ocorra) adaptado para a comunicação coletiva, fundamentado na cooperação dos participantes e na socialização de informações e conhecimentos (RHEINGOLD, 1998).

Atualmente o E-group é um ambiente de trocas de informação por meio de emails, que possibilita a troca de mensagens instantâneas, arquivamento de material (artigos, conclusões de fóruns, fotos, vídeos), criação de fóruns e enquetes. Permite criar também espaço para troca de mensagens relativas a um tópico específico ou para reunir um grupo de interesse comum em listas de discussão.

$\mathrm{Na}$ investigação de doutorado, no qual este texto se remete, nos propomos a investigar o processo de constituição, desenvolvimento e consolidação de um grupo de trabalho colaborativo envolvendo a pesquisadora e professores de História da Rede Municipal de Ensino de Belo Horizonte (RME/BH), interessados em conhecimentos e práticas pedagógicas mediadas pelas Tecnologias de Informação e Comunicação Aplicadas à Educação (TICE), no ensino e aprendizagem daquela disciplina.

Além da pesquisadora, que atua na $\mathrm{RME} / \mathrm{BH}$, o grupo foi composto por cinco professores de História do Ensino Fundamental ( $2^{\circ}$ e $3^{\circ}$ ciclos), que lecionam em escolas públicas de Belo Horizonte/MG, e uma professora recém-formada que não pertencia à RME/BH. O grupo foi criado em julho de 2007 e, atualmente, continua com seus encontros presenciais mensais e virtuais.

Foi escolhida a ferramenta E-group do servidor Yahoo pela facilidade e praticidade na utilização. Além disso, a maioria dos professores do grupo já possuía uma conta de $e$-mail do Yahoo.

Nessa investigação, o E-group constituiu-se num espaço coletivo de debates de ideias, de troca, de estudo e de discussão de textos, de avaliação dos encontros presenciais, de sugestões, de construção de textos coletivos, entre outros. 
O E-group foi escolhido por ser, entre os múltiplos ambientes existentes que podem consentir a colaboração, o que mais vastamente se constitui e o que apresenta mais facilmente aos usuários. Não necessita de programas especiais, aceita a participação assíncrona e existe em abundância.

Avistamos, nas interações virtuais, a possibilidade dos seguintes elementos favorecedores, já observados por Caimi (2006):

a) interrogar os processos naturalizados de sala de aula e as posições estabelecidas de saber centradas no educador;

b) oportunizar lugares de dizer a todos, simultaneamente, potencializando o tempo pedagógico;

c) beneficiar as reflexões e a produção cooperativa e colaborativa, gerando amplo material para a análise compartilhada e o redimensionamento do trabalho através dos registros postados no ambiente virtual; d) experimentar um processo de construção de conhecimento.

Vários são os benefícios apresentados na participação em grupo de discussões em ambientes de comunicação assíncrona mediada por computadores. Rojo (1995) evidencia alguns:

- Travar contato com ideias correntes, lançamentos e eventos no campo de estudo;

- Ter a oportunidade de obter rapidamente respostas de qualidade;

- Conseguir materiais de valor, ou indicações de como conseguí-los;

- Aprender sobre o meio em si;

- Adquirir o sentimento de fazer parte de uma comunidade de interesse;

- Ter a oportunidade de expressar ideias e sentimentos;

- Ter a oportunidade de intensificar contatos com pessoas compartilhando interesses similares.

As listas de discussão existentes na internet possibilitam a partilha de informação, conhecimento, permitindo aos participantes analisarem e discutirem a perspectiva dos outros, refletirem sobre o seu próprio conhecimento e apresentarem seu ponto de vista. Elas oferecem oportunidade ao indivíduo de aprender por meio de atividades desenvolvidas colaborativamente. Essa interação é um fator expressivo para a construção do próprio conhecimento e do percurso pessoal de aprendizagem. 
Nesse sentido, o conhecimento está constantemente sendo distribuído e renovado, e passa por interpretações, experiências e opiniões.

As escolhas metodológicas da tese bem como a análise dos dados foram norteadas pela seguinte questão: Que contribuições a participação em um grupo colaborativo, cujo foco são as TICE, pode trazer para o desenvolvimento profissional de professores de História da RME-BH?

A abordagem metodológica adotada foi a qualitativa, tendo um caráter exploratório na medida em que se propôs a identificar e a conhecer as características dos professores participantes (quem são enquanto profissionais e o que pensam acerca do processo de ensino e aprendizagem) e suas práticas pedagógicas.

Destacaremos, neste artigo, exemplos de colaboração e interação de um grupo de sete professores de História - por meio da ferramenta online E-group, como e-mails, reflexões postadas, enquetes e construção coletiva de textos, dando enfoque à potencialidade dessa ferramenta.

\section{Resultados}

\section{A colaboração on-line como ferramenta para o desenvolvimento profissional dos} professores

Apresentamos os principais resultados da análise dos conteúdos das mensagens do E-group postadas pelos professores.

Verificamos várias iniciativas de estímulo ao ambiente virtual, tais como: referências aos sites ali postados e recomendações de uso pelos colegas; prontidão de resposta quando se trata de ajudar algum colega em eventual dificuldade técnicooperacional, relativa ao uso do ambiente; entre outras.

Olá colegas, talvez já tenham lido as reportagens (refere-se a reportagem "a História como ela é" publicada na carta capital) mas, se não [...].

Oi, pessoal, Eu fiz um blog para que os alunos da tarde façam comentários sobre as aulas de História em 2007. A repercussão foi ótima. Já tem mais de 100 comentários. (P.) ${ }^{3}$

Se vocês tiverem tempo deem uma olhada. Essa é uma atividade que possibilita alguns ganchos com outras disciplinas, principalmente Português. (H.).

\footnotetext{
${ }^{3}$ Nomes fictícios.
} 
Também se destaca a forma de lidar com os referenciais teóricos (tanto sobre as TICE quanto sobre o ensino de História mediado pelas tecnologias digitais), ultrapassando leituras mecanicistas e, em alguns casos, estéreis dos textos. Assim, os professores tratam as leituras propostas de modo dinâmico, comentando, discutindo e esclarecendo pontos dúbios. O grupo se autogerencia enquanto aproveita a teoria estudada para esclarecer, ampliar e redimensionar as questões advindas da prática, ao mesmo tempo em que tornam essas questões instrumentos para questionar, refutar e/ou reafirmar as teorias.

O ambiente virtual constituiu um espaço fértil para a colaboração, sendo espaço de discussão, análise, e, principalmente, de construção coletiva de saberes, mediante a reflexão e a teorização sobre a própria prática docente no encontro/confronto com a prática docente do outro.

Além de se constituir em contexto de desenvolvimento profissional, as interações no ambiente virtual ampliaram o vínculo afetivo entre os professores do grupo:

H., seu blog está muito bacana! Parabéns! Quando eu "crescer" quero ser que nem você! Sujeitos a pampas! Abraços do colega (com muita honra). (P.).

Pessoal, passar a tarde do dia 27 no Mercado Central foi muito agradável. Bebemos, comemos, conversamos, rimos e fortalecemos o grupo. $\mathrm{Na}$ próxima vez, vamos tentar levar o grupo todo, pois momentos como esses são inesquecíveis. Valeu. (H.)

Uma característica do ambiente virtual - a não presença - cria uma dinâmica distinta na qual as pessoas podem se comportar de modo diferente da forma como o fazem nos encontros presenciais: participar mais ou menos, se expressar mais e de formas variadas ou o oposto.

Os próprios professores destacaram algumas características do E-group que favoreceram a consolidação da colaboração no grupo como, por exemplo, seu caráter democrático, a possibilidade de refletir sobre o escrito, a potencialização da autoria, a articulação e a possibilidade de interagir com os colegas de forma assíncrona.

O professor H. ressalta que o E-group é um espaço que é importante tanto para resolver questões de ordem prática quanto questões pedagógicas e teóricas. Seu caráter democrático permite que todos se expressem de forma democrática.

Como dissemos na última reunião, o grupo anda ligeiro no virtual. Muitas questões são resolvidas no E-group, algumas de ordem prática, como a que horas reunir, o que levar de lanche, qual é o roteiro da reunião, etc., outras de 
ordem conceitual como essa agora, ou sobre Webquest ou sobre a prática pedagógica. Outro ponto positivo que vejo nas listas de discussão é o seu caráter democrático, pela oportunidade de todos se expressarem livremente e serem ouvidos pelos demais. Concordo com a Andréia quando ela diz que essa ferramenta foi essencial para a consolidação do nosso grupo, pois ela nos aproximou. (H.).

O professor M. destaca algumas vantagens do E-group, como:

(1)-o grupo virtual possibilita reflexões mais profundas: há um tempo para planejar as respostas. Há um tempo para escrever e, novamente, refletir sobre o escrito. Esse tempo faz muita diferença no debate. Daí eu acreditar que há aprofundamento. Não estou querendo dizer com isso que esse debate é melhor do que o outro, o presencial. Mas é diferente. O outro debate também tem a sua importância: o olho no olho, as interações, as sensações, o corpo falando (e às vezes de modo antecipado).

(2)-o grupo virtual nos possibilita entender bem uma das potencialidades da internet: a autoria. Quanto conhecimento já produzimos nesse grupo. Nós não vamos escrever um livro? O grupo virtual tem dado um caldo muito bom para pensarmos no livro.

(3)-o grupo virtual é articulador. Essa perspectiva que o H. apontou: organiza o trabalho e nos articula no campo conceitual. Eu apontaria ainda um terceira linha: ele me lembra do compromisso que assumi com todos vocês e me possibilita participar com o tempo que tenho. (M.).

Entretanto, é preciso salientar que o ambiente virtual, nos primeiros momentos, foi subutilizado. Ainda que o grupo discutisse sobre a importância do uso das TICE nos encontros presenciais, mostrando desenvoltura e facilidade de expressão das ideias, demorou cerca de dois meses para que as mensagens postadas no E-group se tornassem rotineiras.

O professor J. ressalta que, no seu caso, o "pouco contato com as listas de discussão" e a falta de "paciência de ficar digitando" foram fatores determinantes da falta de interação no ambiente virtual.

O professor H. destacou como as mensagens no E-group mudaram de formato, tornando-se mais afetivas e menos formais.

Já estamos conseguindo nos comunicar sem tanta formalidade como era no começo. As mensagens são mais soltas. Há um afeto maior entre a gente. $\mathrm{O}$ P. usa todos os recursos! Cor de fonte, carinhas! (H.).

Eu gosto de ver suas mensagens P.! Todas coloridas! (He.).

O professor M. levanta a questão se "esse processo (se referindo a aproximação à tecnologia) é o mesmo com os alunos" (M. 28/11/07). Apesar de essa questão não ser 
respondida no momento em que foi postada, o relato de experiência da criação de um blog, realizado pelo professor H., sobre a postagem de mais de cem comentários no blog criado por ele, parece evidenciar que para os alunos o processo não é tão doloroso como é para os professores.

Os professores, ao longo dos encontros, reconhecem essa facilidade dos alunos já que os mesmos, ao contrário dos professores, são "contemporâneos da tecnologia":

[...] faço um rascunho manuscrito e depois passo a limpo para o computador ou vou direto à máquina [...]. Sou um dinossauro em fase de transição. Alguém, já nascido na era do Império Microsoft Windows, seria abraçado por essa dúvida atroz? Duvido. (P.).

[...] os meninos buscam os sites, acham o que os interessa. (M.).

[...] são muito menos resistentes que nós. (V.).

[...] os professores são os mais resistentes. (He.).

No entanto, ainda que os professores acreditem que o uso das TICE auxilie na atividade profissional, o interesse e a habilidade em lidar com o computador podem ser um caminho, uma estratégia para "abrir caminhos" para os alunos. Eles ressaltam também as dificuldades de utilização das mesmas que acabam por fazer com que o trabalho com os livros didáticos, como veremos mais adiante, "ganhe" do trabalho com as TICE: "o livro está lá na pasta do menino os computadores não funcionam" (H.).

Em síntese, os professores do grupo - ao se apropriarem do E-group - não apenas aproveitaram um espaço extra para discutir, refletir em conjunto e construir saberes, mas se aproximaram, eles próprios, da tecnologia que reconheciam ser importante para o ensino e aprendizagem de História.

Durante os dois anos (2007 a 2009) no qual o ambiente E-group foi analisado, 756 mensagens foram postadas. No intuito de melhor analisá-las, agrupamos em indicadores mais frequentes ${ }^{4}$ como elucida o gráfico abaixo:

\footnotetext{
${ }^{4}$ Inspiradas em Caimi (2006).
} 


\section{Gráfico 1: Conteúdo das mensagens}

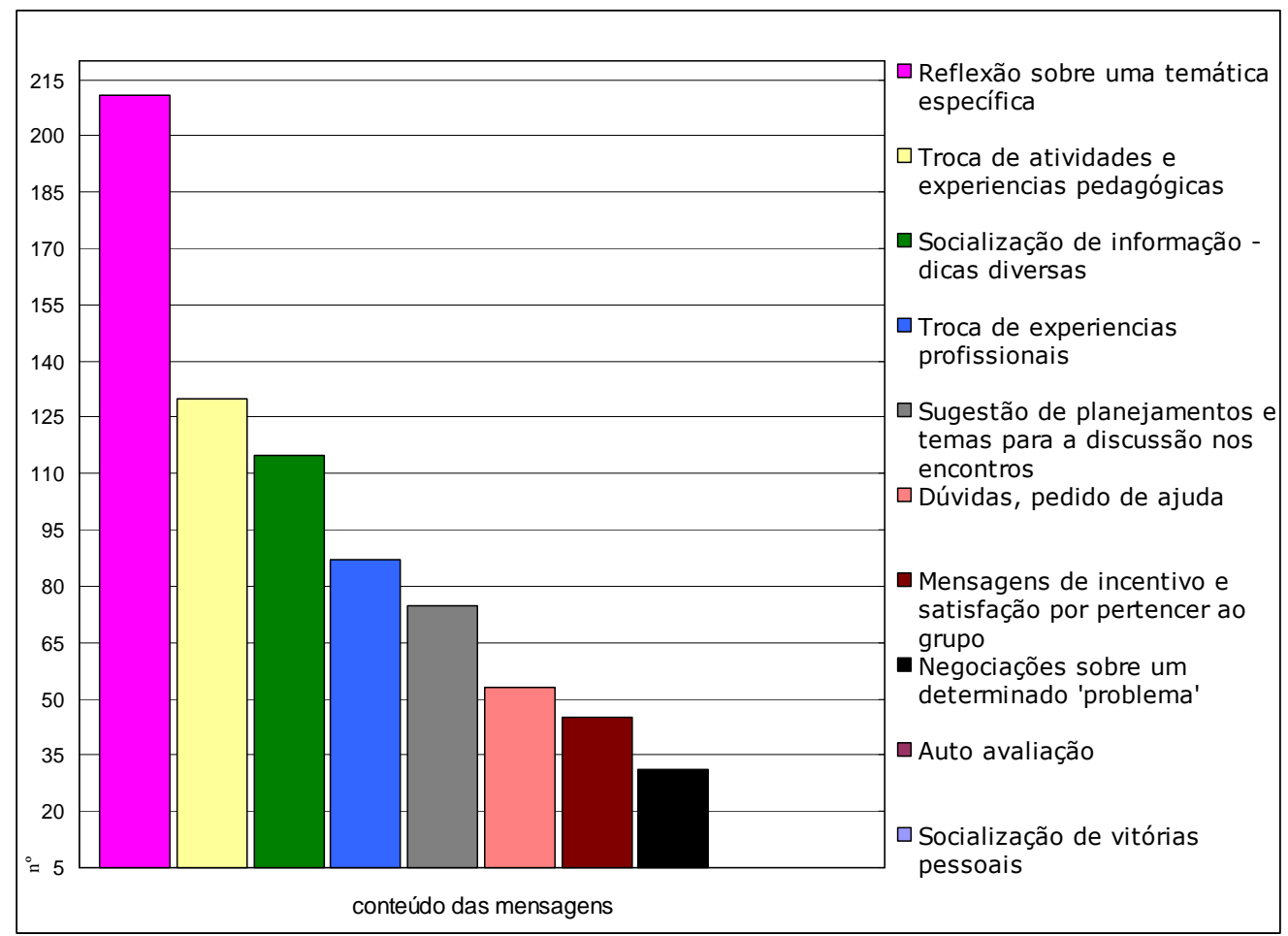

Fonte: (FERREIRA, 2010, p. 219).

Esses indicadores de colaboração, de forma geral, mostraram que o ambiente virtual constituiu em um fértil e rico espaço educativo para a colaboração, abrindo possibilidades de discutir, analisar, relacionar, sintetizar, generalizar, enfim, construir significados, mediante a reflexão e a teorização sobre a própria experiência no encontro/confronto com a experiência do outro. Além das aprendizagens de natureza cognitiva operadas por meio das discussões teóricas, da troca de experiências, as interações no ambiente virtual ampliaram o vínculo afetivo e a descontração.

Indagados a respeito da utilidade de uma lista de discussão no desenvolvimento profissional de professores, os participantes do grupo ressaltaram que a mesma é um excelente meio de socialização e troca de conhecimentos, podendo ser um instrumento potencializador de mudança da forma de interação entre pessoas.

Inseridos em um contexto no qual a organização escolar não possibilita espaços de trocas de experiência e autoformação, os professores vêm se isolando cada vez mais. Nesse sentido, este estudo verificou que a ferramenta E-group pode ser uma estratégia pedagógica para que os professores possam compartilhar experiências com os colegas, construir projetos colaborativos e refletir sobre sua própria formação. 
Em síntese, os professores se apropriaram de um instrumento (novo para a maioria), para desenvolveram as habilidades necessárias para utilizá-lo e o fizeram intensamente. Eles trouxeram para o E-group suas preocupações, angústias, dúvidas, sugestões, dificuldades, mas também, suas conquistas e aprendizagens. O conteúdo das mensagens enviadas no E-group evidenciam que todos demonstraram interesse pelas questões trazidas pelos colegas e transformaram cada uma delas em uma possibilidade de olhar para si, interrogando as próprias práticas e experiências. Entendemos que esse é um dado essencial para o desenvolvimento profissional de professores.

Dessa forma, o ambiente virtual - aspecto não planejado inicialmente - mostrouse um contexto extremamente rico em oportunidades de desenvolvimento profissional e de colaboração.

\section{Considerações Finais}

A parceria entre professores não é fácil e exige o estabelecimento e a manutenção de relações duradouras, como a produção de um novo discurso pedagógico, mais do que apenas uma atitude de consumidores de conhecimento produzido pela investigação educacional (DAY, 1999). Nesse sentido, a colaboração entre os professores pode ser o caminho para a realização pessoal, na profissão docente e para a inovação e qualidade do ensino.

Entendemos que o conhecimento é produzido socialmente, que os profissionais têm muito a oferecer uns aos outros e que a troca de experiências e a partilha de saberes são essenciais. Dessa maneira, a colaboração, como forma de relacionamento que privilegia o respeito mútuo, a parceria, o estabelecimento de metas comuns e a diluição da hierarquia, é uma modalidade comunicativa para o desenvolvimento profissional de professores.

Compreendemos a importância das trocas, dos diálogos e das interações nos fóruns de discussão para a construção dos vínculos entre os participantes. O ambiente virtual de aprendizagem pode ser considerado um espaço de possibilidades de expressão, especialmente para aquelas pessoas que são mais tímidas para se expressar oralmente.

No presente trabalho, o E-group evidenciou ser uma ferramenta e uma estratégia facilitadora das interações e do processo de desenvolvimento profissional dos professores, já que permite a colaboração, a interlocução entre os pares, a reflexão e o 
aprofundamento da temática de estudo (as TICE no ensino e aprendizagem).

Observamos ainda que o ambiente digital constituído ampliou o espaço para a reflexão acerca da estrutura do próprio currículo de História, sobre o porquê ensinar História, o que ensinar e como fazê-1o ${ }^{5}$.

Nosso estudo permitiu demonstrar que o Ensino de História associado às TICEs, pode demonstrar mais sintonia com as mudanças que vêm se processando na sociedade e com novas gerações e, assim, vislumbrar novos temas e novas maneiras de aprender e ensinar incorporando a ideia de que essa é uma disciplina viva e construída a partir do presente.

\title{
Collaboration in asynchronous communication environments: a strategy for the professional development of history teachers
}

\begin{abstract}
In this article we explore the construct of cooperation differentiating collaboration. We highlight how online collaboration environments for asynchronous communication can be an aggravator of the professional development of teachers of history. We present examples of this interaction mediated by e-group, from the results of doctoral research on the professional development of history teachers of $\mathrm{RME} / \mathrm{BH}$, which experienced a process of formation and consolidation of a collaborative group mediated by the TICE. Based on the concept of professional development adopted by Garcia (1999) - as the set of processes and strategies that facilitate teachers" reflection on their practice, which helps teachers manage practical knowledge, strategic and able to learn from your experience - we believe that the collaborative group can decisively contribute for teachers professional development.
\end{abstract}

Key words: Asynchronous Communication; Collaboration; Discussion List; Professional development; TICE.

\footnotetext{
${ }^{5}$ Para o ano de 2011, o grupo escolheu as temáticas "Proposições Curriculares de História", e "Ensino de História nas séries inicias mediado pelas TICE”, como foco de reflexões.
} 


\section{Referências}

CAIMI, Flávia E. Processos de conceituação da ação docente em contextos de sentido a partir da Licenciatura em História. 2006. 271 f. Tese (Doutorado em Educação). Universidade Federal do Rio Grande do Sul, Porto Alegre.

COSTA, G. L. M. O professor de matemática e as tecnologias de informação e comunicação: abrindo caminho para uma nova cultura profissional. 2004. $204 \mathrm{f}$. Tese (Doutorado em Educação). Universidade Estadual de Campinas (UNICAMP), Campinas.

DAY, C. Desenvolvimento profissional de professores. Porto: Porto Editora, 2001.

DILLENBOURG, P. What do you mean by collaborative learning? In: DILLENBOURG, P (Ed.). Collaborative-learning: cognitive and computational approaches. Oxford: Elsevier, 1999.

FERREIRA, Andréia de Assis. Desenvolvimento profissional de professores de História: estudo de caso de um grupo colaborativo mediado pelas tecnologias de informação e comunicação aplicadas à educação. 2010. 259 f. Tese (Doutorado em Educação), Universidade Federal de Minas Gerais, Belo Horizonte, Brasil.

GARCÍA, C. Formação de Professores: para uma mudança educativa. Porto: Porto Editora, 1999.

PONTE, João P. Da formação ao desenvolvimento profissional. In: ACTAS DO PROFMAT. Lisboa: Associação dos Professores de Matemática, 1998, p. 27-44.

RHEINGOLD, Howard. The Virtual Community. 1998. Disponível em: <http://www.rheingold.com/vc/book/>. Acesso em: 16 maio 2010.

ROJO, Alejandra. Participation in Scholarly Electronic Forums. 1995. 340 f. Thesis (Ph.D.). University of Toronto, Toronto, Canadá. Disponível em: <http://openlibrary.org/books/OL18693999M/Participation_in_scholarly_electronic_for ums>. Acesso em: 25 fev. 2010.

SILVA, B. A tecnologia é uma estratégia. In. DIAS, Paulo; FREITAS, Varela de (Org.). Actas da II Conferência Internacional Challenges 2001. Braga: Centro de Competência da Universidade do Minho, 2001. p. 839-859.

TORRES, P. L.; ALCÂNTARA, P. R.; IRALA, E. A. F. Grupos de consenso: uma proposta de aprendizagem colaborativa para o processo de ensino-aprendizagem. Revista Diálogo Educacional, Curitiba, v. 4, n.13, p. 129-145, 2004. 